\title{
A gas supply system criticality assessment
}

\author{
B. Jokšas, I. Žutautaitė \& E. Ušpuras \\ Lithuanian Energy Institute, Lithuania
}

\begin{abstract}
Heat and electricity systems are very strongly associated with fuel provision systems. Natural gas is one of the main fuels used in the heat and electricity generation process. So it is important to ensure that the infrastructure of natural gas supply remains as robust and reliable as possible. System criticality level is one of the most important indicators of reliable power supply. The simulation of a gas network was implemented by the optimization method of maximum flow. In this paper the authors present a gas supply system criticality assessment based on some results of risk analysis. The pilot calculations were performed for a closed hypothetical energy system. The results of such analysis may also be incorporated into the development of an infrastructure criticality analysis.

Keywords: infrastructure, gas network, criticality.
\end{abstract}

\section{Introduction}

The county's sociality and economic prosperity depends on functionality of its infrastructure. Each system of the country is closely related with each other. Common case that the disruption in one system of the country influences other dependent systems (directly and indirectly) and it could tragically affected the final users.

Elements of the infrastructure are dependent on each other by functionality relations, and element functionality depends on availability of other systems elements. Disturbances on the system could be internal or external. So this issue to analyse criticality and reliability of infrastructure should be one of the main in order to insure the safety of the country or all continent. The research in this area conducted in various aspects.

The plenty of scientific papers of infrastructure criticality analysis shows topicality of this kind research. Some authors used topological analysis methods to find high criticality network components in the energy infrastructure system 
[1]. This analysis is important to identify important elements in the network in topological aspect, but it does not take into account elements functionality relations in the system. These methods are usually used for individual systems as like electricity network water supply system, gas supply system and etc. [2-5].

Some authors propose to use an agent-based behaviour model [6, 7]. It allows one to represent dynamic system behaviour, but this method does not take into account the system elements' reliability.

Other authors used structural analysis to identify vulnerable and critical elements in the system [8].

Mathematical modelling and optimization of the Distributed Energy Supply System are investigated by Fubara et al. [9]. The created model is applied to demonstrate the domestic supply system in the UK. The proposed model-based framework for assessing micro-CHP technologies for domestic energy supply reveals the effects of technology configuration on primary energy consumption. Authors used balance optimization methods for modelling and analysed energy system in economical aspect.

Some authors analyse separate systems of infrastructure as like gas and electricity systems [10]. Authors analysed infrastructure expansion planning for ecological aspect. The network planning approach, which they created, allows to make assessment into the interactions between gas and electricity networks.

Some authors analysed critical infrastructure (gas and oil systems) which could make huge ecological catastrophe in case of failure [11]. They proposed a holistic and transparent approach of multi-criteria decision analysis for evaluating and comparing alternative decommissioning options across key selection criteria, including environmental, financial, socioeconomic, and health and safety considerations.

In this paper authors analyse the relationship connections between gas supply system and electricity and heat systems. The method for the assessment of infrastructure criticality was developed. Proposed method allows identifying the most critical components of the gas supply system and determining their impact on electricity system.

\section{Energy system description}

This paper is a continuation of the previous work [12], and it analyses a closed hypothetical energy system. This system is composed by six cities (final users), fuel supply system, and heat and power generation system. System elements are connected with respect to functionality relations. Some different energy generation technologies are used in this model. One of the assumptions is that analysed system during cold period, when heat demands are the higher. System simulated by quarter period, assuming that the system is a closed (without opportunity to import electricity). This developed methodology allows to assess the country ability to satisfy user demands by own resources and to ascertain the critical elements in the energy system. The disruption of this element affects energy system (final users). The system functionality scheme is presented in figure 1. 


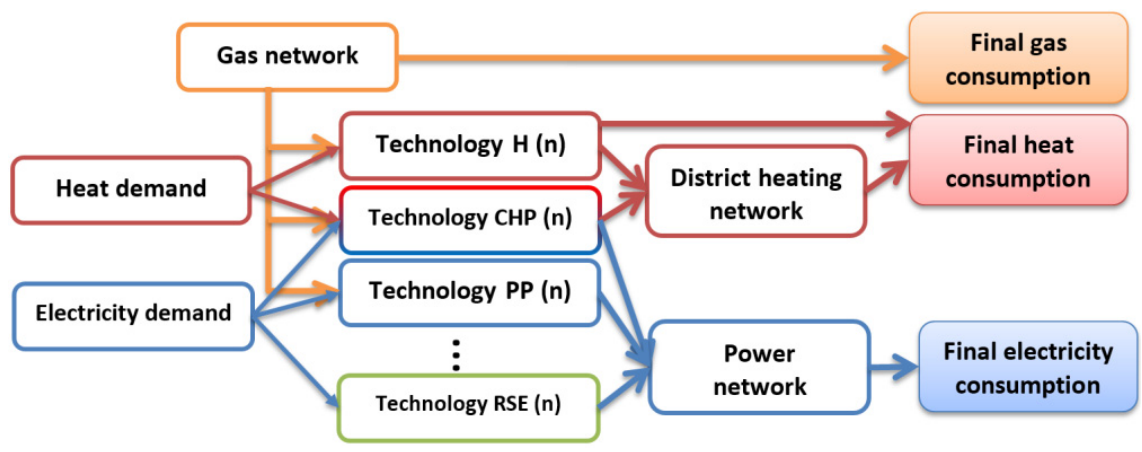

Figure 1: The system functionality scheme.

The analysed energy system is composed of 6 combined heat and power plants (CHP) (installed capacity of heat 2641.8 MW and power 762.8 MW), 33 boiler houses $(\mathrm{BH})$ (installed capacity of heat $4091.3 \mathrm{MW}$ ), 19 biofuel boiler houses $(\mathrm{BIOH})$ (installed capacity of heat $376.4 \mathrm{MW}$ and power $31 \mathrm{MW}$ ), 2 power plants (PP) (installed capacity of power $1945 \mathrm{MW}$ ), 2 hydro power plants (HP) (installed capacity of power $125.7 \mathrm{MW}$ ) and 2 wind parks (WP) (installed capacity of power 201.7 MW). As the main fuel in the heat and electricity generation, natural gas is used. The gas supply system is composed of 89 main pipelines; gas is supplied to the system from two sources (imported from neighbouring country $31.2 \mathrm{Mm}^{3} /$ day and terminal of liquid natural gas 11 $\mathrm{Mm}^{3} /$ day). Oil is used as an alternative to fuel in the CHP. The failure rates of CHP and PP are estimated by statistical data [13-15].

The energy generation technology, used in the model, could be characterized by the following expression:

$$
\vec{E}_{i}=F\left(T_{i}, f_{j i}, \alpha_{i}, d_{z i}\right)
$$

where $i$ - the type of technology, $i=1, \ldots, n ; n$-number of CHP, PP, BH, HP, WP of considered energy system; $F(\cdot)$-functional dependency describe generation technology work; $T_{i}$ - the technical characteristics of $i^{\text {th }}$ generation technology; $f_{j i}$ - the quantity of $j^{\text {th }}$ fuel type provided to $i^{\text {th }}$ generation technology; $\alpha_{i}$ - the availability rate of $i^{\text {th }}$ technology; $d_{z i}-z^{\text {th }}$ consumer demand of $i^{\text {th }}$ technology.

The developed model analyses energy system, when elements operation statements (operates or not) are defined by its failure probability using random number generator. The electricity system dependence on gas supply systems reliability is analysed in this paper.

Gas supply system is composed of different diameters and lengths pipelines. The maximum flow of each pipeline is assessed with respect of diameter, length and pressure of the supply system [16]. The maximum flow mathematical optimization method was used to simulate the gas supply system. The demands of natural gas are estimated depending on the heat and electricity generation 
technologies efficiencies. The gas supply network is composed as a directed graph (balance should be in connections). The failure rate of gas pipeline is estimated by statistical data of European Gas pipeline Incident data Group (EGIG) [15]. In this paper we analysed the situation when gas supply to the country is of $100 \%$.

The heat demand of the user is also distributed for generation technologies by the priority mathematical optimization method. The optimization is performed to maximize energy generation for each end user. It enables the implementation of ecological /economical eligibility requirements. First priority for heat generation is given for bio boiler houses. The second priority is given for CHP, and the lover priority is given for boiler house (primary fuel is gas). Electricity demand also distributed for generation technologies by economical aspect. Preference is given to the technologies using renewable energy sources such as hydro power plants, wind parks, etc.

\section{Criticality assessment method}

The gas supply system is decomposed into elements. Decomposition is performed according to the pipeline filiations and pipe diameter. This is performed in order to determine the influence of each element of pipeline to electricity system.

The criticality of the $k^{\text {th }}$ element may be estimated using the reliability indicators of final consumers obtained in the case where the $k^{\text {th }}$ element is out of order:

$$
C^{(k)}(t)=1-\sum_{i=1}^{M} c f_{i}^{(k)}(t) \cdot \beta_{i} \quad k=1,2, \ldots, N
$$

where $N$ - number of the elements in the energy system; $c f_{i}^{(k)}(t)$ - the reliability indicator that shows how much the energy demand is satisfied for the $i^{\text {th }}$ element; $\beta_{i}$ - the weighted coefficient of the $i^{t h}$ final consumer within system (for instance, weighted coefficients are estimated with regards to the energy demand of consumer, and they satisfy equality $\beta_{1}+\ldots+\beta_{M}=1 ; M-$ number of the final consumers in the energy system). For instance, $C^{(k)}(t)=1$ means that disruption of the $i^{\text {th }}$ element work stops the operation of all energy infrastructure at time moment $t$.

Our developed criticality assessment method consists of 5 steps (structural scheme is presented in figure 2):

Step 1: $\quad$ Analysis of statistical data and format inputs data for model;

Step 2: Monte-Carlo method is used to define the availability of system technologies that depend on statistical failure rate;

Step 3: Simplex optimization method is used for the performing distribution of heat and electricity demands for generation 
technologies. Maximum gas flow distribution is performed as well;

Step 4: Generation technologies assess the amounts of productions dependent on supply system functionality.

Step 5: The criticality assessment of electricity system and heat system is performed.

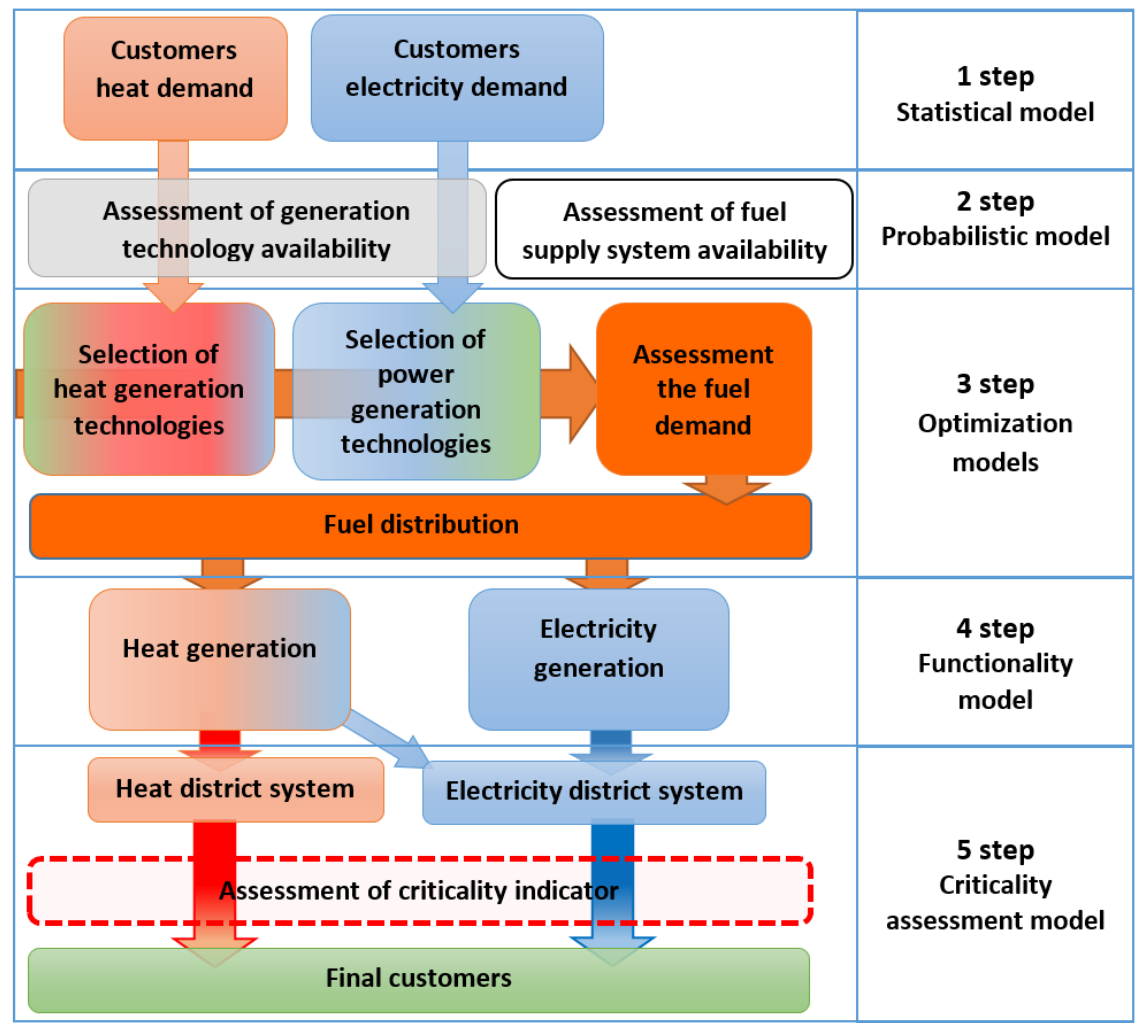

Figure 2: Structural scheme of system criticality assessment method.

Two approaches for the assessment of element criticality with respect to system functionality are used:

Approach 1: Calculations are performed with assumption that only one element is out of order using the method presented in figure 2 (in this case step 2 is skipped). Obtained result is estimate of system criticality.

Approach 2: calculations are performed with assumption that one element is out of order, operating statement of other elements is defined with respect to its failure probability. Calculations are performed according to the method presented in figure 2 . In 
this case, element criticality $X$ is random value, its conditional probability distribution is obtained using Monte Carlo method.

Approach 1 is hypothetic and does not represent realistic scenarios of system operation: failure probabilities of other system elements are not equal to zero. Thus, approach 2 can be used to obtain criticality results of more realistic situation.

The obtained probability distribution is used to calculate characteristics of element criticality:

- probability of null value of criticality $P\left(X=0 \mid e_{i}\right)$ in case when analysed $i^{\text {th }}$ element is out of order or opposite $P\left(X>0 \mid e_{i}\right), i=1, \ldots, N$;

- $\quad$ average criticality (or median);

- $\quad$ standard deviation of criticality.

\section{Numerical example for criticality assessment}

The pilot calculations were performed of criticality assessment of closed hypothetical energy system. The description of the configuration of the analysed energy system is presented in section 2, the scheme is presented in figure 3 as directed multigraph: pipelines, $\mathrm{CHP}, \mathrm{BH}, \mathrm{BIOH}, \mathrm{PP}, \mathrm{HP}, \mathrm{WP}, \mathrm{LNG}$ (liquefied natural gas terminal) and final users are presented as nodes; nodes are connected if its corresponding elements have functional relation.

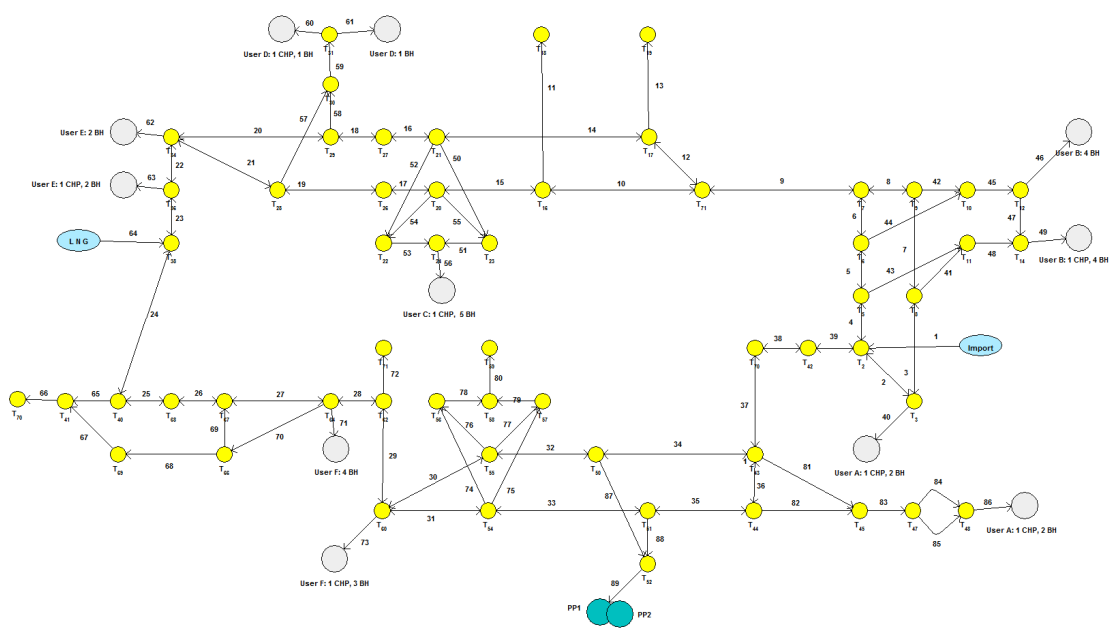

Figure 3: The scheme of analysed energy system. 
For the calculations, the demands of heat and electricity were fixed according to statistical data of Lithuania (winter season was chosen).

Approach 1: the estimates of criticality of each ith element are presented in figure $4, \mathrm{i}=1, \ldots, 89$.

Approach 2: analysed ith element is out of order, operating statement of other elements is obtained using random number generator with respect to its failure probability: scenario of elements availability is generated (generation process is repeated 100,000 times). The estimate of system criticality is calculated in each case. Obtained conditional probability distributions of elements criticality are presented in figure 5.

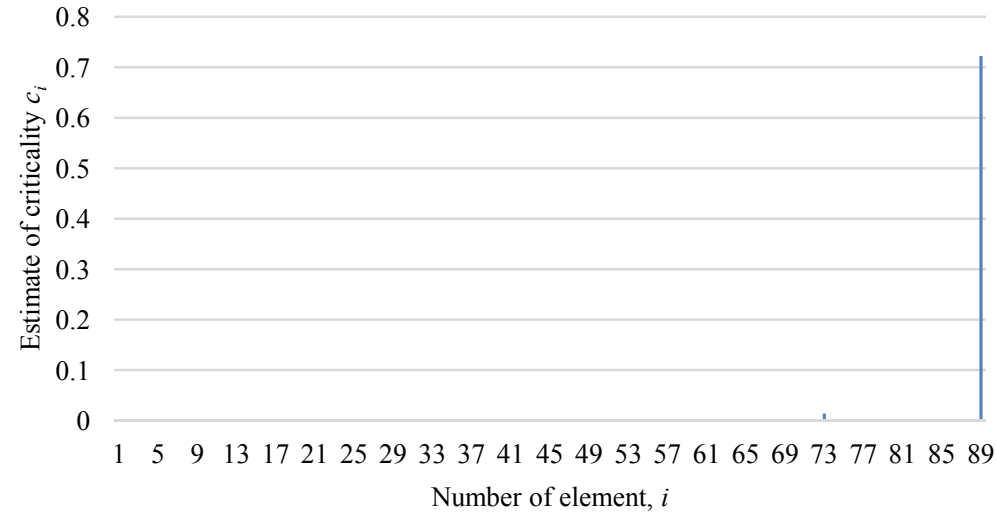

Figure 4: Estimates of criticality (approach 1).

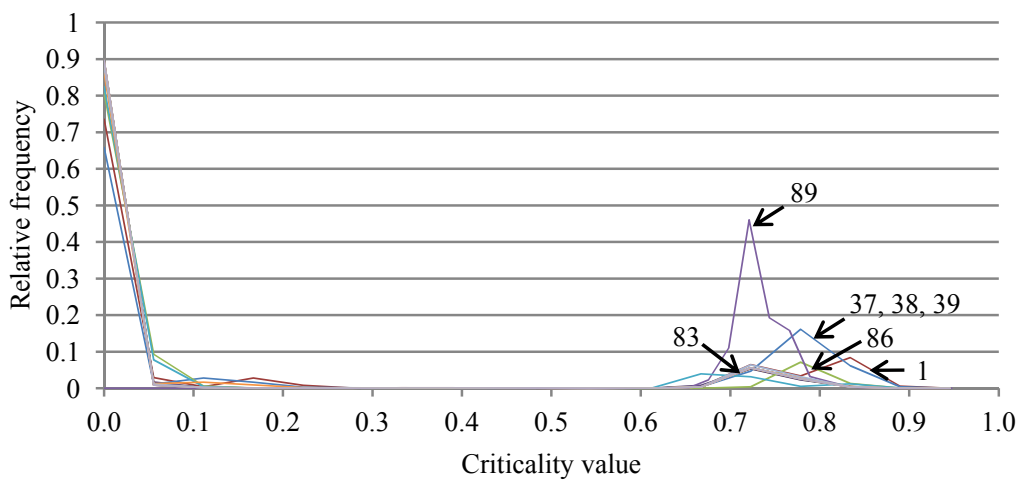

Figure 5: Relative frequency distribution of $i^{\text {th }}$ element criticality, $i=1$, ...,89 (approach 2). 
The obtained probability distribution is used to calculate characteristics of element criticality: probability of non-null criticality $P\left(X>0 \mid e_{i}\right), i=1, \ldots, 89$ (see figure 6); mean value of criticality (see figure 7).

Figures 6 and 7 show that the most critical gas pipeline element is the $89^{\text {th }}$ element. It connected power plants with main gas network. When this element is out of order the probability of non-null criticality is equal to 1 and the maximum mean value is equal to 0.73 . The other most critical pipeline segments are numbers: 37,38 and 39 . The mean value of criticality of these elements is 0.23 and the probability of non-null criticality is equal to 0.34 . This group of element connected major customers and they are important transmission elements in the gas network.

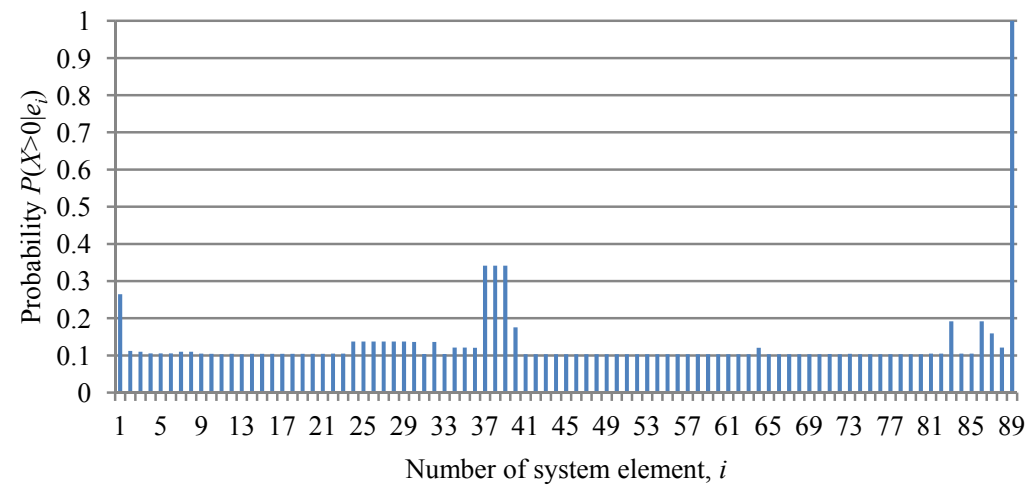

Figure 6: Probability of non-null criticality in case of analysed $i^{\text {th }}$ element is out of order.

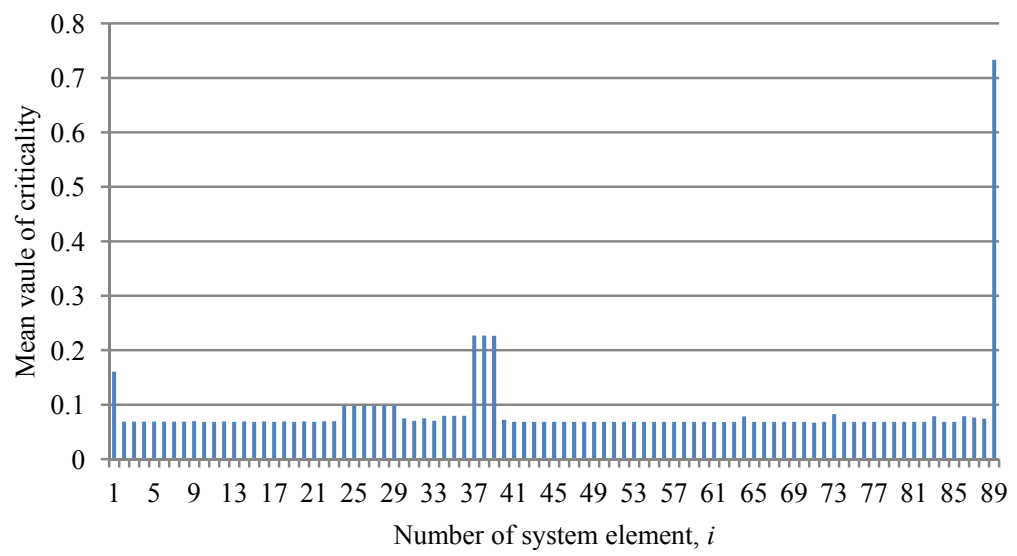

Figure 7: Mean value of criticality in case of analysed $i^{\text {th }}$ element is out of order. 
The other, gas supply system, critical element is $1^{\text {th }}$ element. It is pipeline of gas import. The mean criticality value of this element is 0.16 and it is not higher than the previous mentioned segments. The reason is that, system has diversification of gas supply. The other elements to be noticed are $83^{\text {th }}$ and $86^{\text {th }}$ elements. As showed in the figure 6 the probability value of non-null criticality is 0.19 and it is higher than average probability $(0.07)$ of other system elements.

Research in this area will be continued, the assessment method will include the criticality important measurement in the future works.

\section{Conclusions}

The developed method [12] of assessment of infrastructure criticality was upgraded by application of max flow optimization method for simulation of gas supply, and optimization methods of energy distribution for generation technologies to maximize user satisfaction.

The pilot calculation of criticality assessment of hypothetical system is performed to identify most critical elements and to demonstrate the practical application of the method: gas supply system reliability influence on electricity system was analyzed.

Criticality characteristics for each element of gas supply system (probability of non-null criticality, mean value of criticality) were estimated. The values of probability of non-null criticality are from interval $(0.07 ; 1)$; the mean values of criticality are from interval $(0.067 ; 0.733)$.

The proposed method allows identifying the most critical components of the gas supply system and determining their impact on electricity system. In the analyzed numerical example the most critical gas pipeline element is $89^{\text {th }}$ element (pipelines between power plants and main gas network), the probability of non-null criticality is equal to 1 , the mean value of criticality is equal to 0.73 .

\section{Acknowledgement}

This research was funded by the Grant (No. ATE-04/2012) from the Research Council of Lithuania.

\section{References}

[1] Fang, Y. P., Zio, E., Unsupervised spectral clustering for hierarchical modelling and criticality analysis of complex networks, Reliability Engineering and System Safety, 116, pp. 64-74, 2013.

[2] Kjølle, G. H., Utne, I. B., Gjerde, O., Risk analysis of critical infrastructures emphasizing electricity supply and interdependencies, Reliability Engineering \& System Safety, 105, pp. 80-89, 2012.

[3] Zio, E., Golea, L. R., Reliability Engineering \& System Safety, Volume 101, May 2012, pp. 67-74, ISSN 0951-8320. 
[4] Shuang, Q., Zhang, M., Yuan, Y., Node vulnerability of water distribution networks under cascading failure, Reliability Engineering \& System Safety, Volume 124, April 2014, pp. 132-141, ISSN 0951-8320.

[5] Correa, G. J., Yusta, J. M., Structural vulnerability in transmission systems: Cases of Colombia and Spain, Energy Conversion and Management, Volume 77, January 2014, pp. 408-418, ISSN 0196-8904.

[6] Knoeri, C., Wäger, P. A., Stamp, A., Althaus, H. J., Weil, M., Towards a dynamic assessment of raw materials criticality: Linking agent-based demand - With material flow supply modelling approaches, Science of The Total Environment, Volumes 461-462, 1 September 2013, pp. 808-812, ISSN 0048-9697.

[7] Burgholzer, W., Bauer, G., Posset, M., Jammernegg, W., Analysing the impact of disruptions in intermodal transport networks: A micro simulation-based model, Decision Support Systems, Volume 54, Issue 4, March 2013, pp. 1580-1586.

[8] Filippini, R., Silva, A., A modeling framework for the resilience analysis of networked systems-of-systems based on functional dependencies, Reliability Engineering and System Safety, Volume 125, May 2014, pp. 82-91, ISSN 0951-8320.

[9] Fubara, T. C., Cecelja, F., Yang, A., Modelling and selection of microCHP systems for domestic energy supply: The dimension of network-wide primary energy consumption, Applied Energy, Volume 114, February 2014, pp. 327-334, ISSN 0306-2619.

[10] Chaudry, M., Jenkins, N., Qadrdan, M., Wu, J., Combined gas and electricity network expansion planning, Applied Energy, Volume 113, January 2014, pp. 1171-1187, ISSN 0306-2619.

[11] Fowler, A. M., Macreadie, P. I., Jones, D. O. B., Booth, D. J., A multicriteria decision approach to decommissioning of offshore oil and gas infrastructure, Ocean \& Coastal Management, Volume 87, January 2014, pp. 20-29, ISSN 0964-5691.

[12] Augutis J., Jokšas B., Krikštolaitis R., Žutautaitè I., Criticality assessment of energy infrastructure. Technological and economic development of economy, 2013 (In press).

[13] Security of supply of electricity market Lithuania monitoring report, referred on the 10th of February in 2014 Link to the internet http://www.enmin.lt/lt/activity/veiklos_kryptys/elektra_ir_siluma/MONIT ORINGAS.pdf

[14] Lietuvos energetika 2012. Energy in Lithuania 2012 // Kaunas: Lietuvos energetikos institutas, 2013. p. 17, ISSN 1822-5268.

[15] Gas pipeline incidents, 8th EGIG report, December 2011, Doc. Nr. 11.R.0402 V. 2. 2011.

[16] Lurie, V. M., Modeling of Oil Product and Gas Pipeline Transportation, Wiley-VCH, ISBN: 978-3-527-40833-7, pp. 1-214, 2008. 